УДК 005.95

DOI: 10.28995/2073-6304-2019-3-20-31

Исследование влияния затрат на персонал на добавленную стоимость организации

на основе анализа панельных данных

\author{
Елена А. Алексеева \\ Витебский государственньй технологический университет, \\ Витебск, Беларусь, elena_d@tut.by
}

Аннотация. В статье исследуется влияние затрат на персонал и их отдельных элементов (условно-переменных и условно-постоянных расходов, компенсационных и инвестиционных расходов) на добавленную стоимость на примере организаций, входящих в Белорусский государственный концерн по производству и реализации товаров легкой промышленности (концерн «Беллегпром») за период 2012-2016 гг. По результатам анализа панельных данных на основе тестов выбраны наиболее состоятельные и эффективные модели (FE и $\mathrm{RE}$ ), рассчитаны и интерпретированы коэффициенты регрессии. Полученные результаты могут быть использованы организациями концерна в управлении затратами на персонал для обеспечения роста добавленной стоимости.

Ключевые слова: добавленная стоимость, затраты на персонал, модели анализа панельных данных

Для иитирования: Алексеева Е.А. Исследование влияния затрат на персонал на добавленную стоимость организации на основе анализа панельных данных// Вестник РГГУ. Серия «Экономика. Управление. Право». 2019. № 3.C. 20-31. DOI: 10.28995/2073-6304-2019-3-20-31

\title{
Study of the influence of labour costs on the organization value added based on panel data analysis
}

\author{
Elena A. Alekseeva \\ Vitebsk State Technological University, Vitebsk, Belarus \\ elena_d@tut.by
}

Abstract. The article examines the impact of labour costs and their elements (conditionally variable and conditionally fixed costs, compensation

(C) Алексеева E.A., 2019 
and investment costs) on value added by the example of organizations that are members of the Belarusian State Concern for the Production and Sale of Light Industry Products (Bellegprom Concern), for the period 2012-2016. Following the analysis of panel data and tests, the most consistent and efficient models (FE and RE) were selected, and the regression coefficients were calculated and interpreted. The results can be used by the organizations of the Concern in managing labour costs to ensure the growth of value added.

Keywords: value added, labour costs, panel data analysis models

For citation: Alekseeva EA. Study of the influence of labour costs on the organization value added based on panel data analysis. RSUH/RGGU Bulletin. “Economics. Management. Law” Series. 2019;3:20-31. DOI: 10.28995/2073-63042019-3-20-31

Затраты на персонал организации определяют стоимость рабочей силы, а также являются индикатором ценности персонала для организации. Содержание и структура расходов на персонал отражает приоритеты кадровой политики компании и является объектом анализа и управления для кадровых служб [1-4].

Кадровая политика организации определяет основные направления воздействия на персонал организации для обеспечения его эффективного использования в достижении целей организации. Поскольку персонал становится ключевым ресурсом, определяющим конкурентоспособность и успешность организации, кадровая политика и инструменты ее реализации приобретают особую значимость. Кадровая политика призвана создавать условия для обеспечения потребности в кадрах, привлечения и развития высококвалифицированных и мотивированных сотрудников, способных обеспечить организации успех на рынке.

Одним из важнейших инструментов реализации кадровой политики является определение потребности в финансировании расходов на персонал в соответствии с приоритетами кадровой политики, а также выбор источников финансирования этих расходов.

С вступлением в силу в 2012 г. Постановления Национального статистического комитета Республики Беларусь от 29 августа 2012 г. № 132, а также заменившего его впоследствии Постановления Национального статистического комитета Республики Беларусь от 28 июля 2014 г. №120 была утверждена форма государственной статистической отчетности 6-т «Отчет о составе фонда заработной платы и прочих выплат», в соответствии с которой затраты на персонал стали объектом статистических наблюдений в Республике Беларусь с периодичностью предоставления информация один раз в два года.

ISSN 2073-6304•Серия «Экономика. Управление. Право». 2019. № 3 
В основе упомянутой выше формы 6-т лежит классификация расходов на персонал, основанная на подходе Международной организации труда, в соответствии с которым затраты на персонал включают заработную плату; расходы на социальную защиту работников; расходы на обеспечение работников жильем; расходы на профессиональное обучение; расходы на культурно-бытовое обслуживание, прочие расходы. Это обеспечивает возможность проводить межстрановые сравнения и адаптировать опыт развитых стран в вопросах управления затратами на персонал [5].

Наблюдения за структурой затрат на персонал в промышленности Республики Беларусь за период 2012-2016 гг. позволяют сделать выводы о доминировании в расходах на персонал расходов на оплату труда и обязательные отчисления (в совокупности более 96\%), что свидетельствует об использовании пассивной кадровой политики и отсутствии необходимых инвестиций в персонал и должных мер по развитию человеческого капитала на микроуровне ${ }^{1}$.

Однако теоретические и эмпирические исследования различных авторов доказывают, что человеческий капитал как ключевой ресурс современной организации нуждается в инвестициях и способен обеспечить высокую отдачу на вложенный капитал [6-15].

С целью более детального изучения процессов формирования и использования затрат на персонал было проведено исследование данных статистических наблюдений за организациями, входящими в Белорусский государственный концерн по производству и реализации товаров легкой промышленности (концерн «Беллегпром»), за период 2012-2016 гг. В составе концерна более 100 организаций, которые в совокупности обеспечили 50,5\% объемов производства текстильных изделий, одежды, изделий из кожи и меха в Республике Беларусь в 2018 г. (всего данный вид экономической деятельности осуществляли 1611 организаций). Удельный вес экспорта в общем объеме производства промышленных организаций концерна «Беллегпром» в 2018 г. составил 55,3\%. Между тем производство текстильных изделий, одежды, изделий из кожи и меха составило лишь 3,6\% от общего объема промышленного производства, удельный вес данного вида экономической деятельности в структуре промышленности Беларуси продолжает сокращаться.

Следует отметить, что затраты на персонал в структуре себестоимости при производстве текстильных изделий, одежды, изделий из кожи и меха в Республике Беларусь в 2018 г. составили 30\%, и их удельный вес постепенно растет. В то же время в целом по промышленности доля затрат на персонал в структуре себестоимости

1 Труд и занятость в Республике Беларусь, 2018. Статистический сборник, Национальный статистический комитет Республики Беларусь, 2018. 310 с.

“Economics. Management. Law” Series, 2019, no. 3 • ISSN 2073-6304 
составила в 2018 г. около 15\%, при этом их удельный вес постепенно сокращается².

Анализ состава и структуры затрат на персонал позволил сделать выводы о снижении удельного веса предприятий, финансирующих расходы на профессиональное обучение работников, культурно-бытовое обслуживание, а также выплачивающих доходы по акциям. Снижается удельный вес предприятий, погашающих проценты по кредитам банка для выплаты заработной платы, однако удельный вес этих расходов растет. Доля предприятий, финансирующих расходы по обеспечению работников жильем, растет, однако удельный вес этих расходов падает [5].

Приведенные данные показывают, что назрела необходимость пересмотра кадровой политики и изменения ее приоритетов в пользу активных мер воздействия на персонал, усиления мотивации персонала, увеличения инвестиций в персонал в исследуемых организациях для обеспечения возможности их выживания в долгосрочной перспективе. Для этого необходимо обеспечить кадровую службу информацией для принятия решений на основе современных технологий, позволяющих обрабатывать большие массивы данных с использованием современных эконометрических пакетов [16-18, 15].

Представленное исследование посвящено оценке влияния отдельных элементов затрат на персонал на валовую добавленную стоимость, созданную организацией. Для этого данные из форм статистической отчетности 1-ф «Отчет об отдельных финансовых показателях» и 6-т «Отчет о составе фонда заработной платы и прочих выплат» были преобразованы в панельные данные за периоды 2012, 2014 и 2016 гг., что связано с периодичностью сбора статистической информации о затратах на персонал в Республике Беларусь (один раз в два года). В исходные данные были включены те промышленные организации концерна, данные о которых имелись хотя бы за два из трех периодов наблюдения, а именно 73 организации, в том числе 16 текстильных, 11 трикотажных, 20 швейных и 26 кожевенно-обувных предприятий концерна «Беллегпром».

В качестве зависимой переменной была выбрана валовая добавленная стоимость на одного работника, в качестве независимых переменных были выбраны оплата труда на одного работника, расходы на одного работника, а также элементы расходов на персонал (условно-переменные и условно-постоянные расходы на одного работника, а также инвестиционные и компенсационные расходы на одного работника). Удельные показатели использовались для того, чтобы исключить влияние размера предприятия.

${ }^{2}$ Промышленность Республики Беларусь, 2019. Статистический сборник. Национальный статистический комитет Республики Беларусь, 2019. 199 с.

ISSN 2073-6304•Серия «Экономика. Управление. Право». 2019. № 3 
В качестве критерия отнесения затрат на персонал к условнопеременным и условно-постоянным (в отличие от традиционно применяемого критерия их изменения пропорционально объему произведенной продукции) предлагается использовать зависимость данного вида затрат от количества времени, отработанного работником. Условно-переменные затраты на персонал - это затраты, которые изменяются пропорционально отработанному времени (заработная плата за отработанное время и налоги и отчисления на нее, а также другие виды оплаты труда, зависящие от заработной платы за отработанное время, в том числе премии, надбавки, доплаты и т. п.). Условно-постоянные затраты на персонал - это затраты, которые не зависят напрямую от отработанного времени (оплата за неотработанное время, единовременные выплаты, расходы по обеспечению работников жильем, выходные пособия, доплаты к пенсиям, материальная помощь, оплата путевок, расходы на обучение, расходы на культурно-бытовые нужды, проезд, питание, спецодежда, командировочные и пр.). Дифференцированный подход при распределении этих статей затрат должен усиливать долгосрочную мотивацию и способствовать удержанию и развитию наиболее ценных сотрудников в компании, а также быть стимулом для других работников к росту их результативности и ценности для компании. Таким образом, условно-переменные и условно-постоянные затраты на персонал требуют применения различных экономических механизмов распределения, что позволит усилить трудовую мотивацию и сохранить наиболее ценных работников в компании.

Еще одним важным признаком классификации затрат может стать разделение затрат на персонал на компенсационные и инвестиционные затраты. Компенсационные затраты - это выплаты, связанные с компенсацией уже затраченных работником усилий и/или призванные обеспечить восстановление его трудоспособности (заработная плата за отработанное время и связанные с ней выплаты и пр.). Инвестиционные расходы на персонал - это расходы, которые могут обеспечить компании возможность получения дохода в будущем (расходы на обучение и развитие, оздоровление, обеспечение работников жильем, культурно-бытовое обслуживание и т. п.). Выделение инвестиционной составляющей в расходах на персонал позволит оценить стратегическую направленность управления затратами на персонал и позволит задуматься о сокращении удельного веса выплат, не связанных с возможностью получения дохода в будущем.

В ходе анализа панельных данных было выявлено, что исследуемые параметры имеют значимые связи (таблица 1), однако проверка при помощи теста на линейное ограничение (различие констант) показала, что простая полная регрессия (pooled regression), 
не учитывающая панельную структуру данных, недостаточно хорошо описывает выявленные зависимости.

Таблица 1

Результаты исследования связи между добавленной стоимостью и затратами на персонал

\begin{tabular}{|c|l|l|c|}
\hline № п/п & \multicolumn{1}{|c|}{$\begin{array}{c}\text { Зависимая } \\
\text { переменная }(y)\end{array}$} & \multicolumn{1}{|c|}{$\begin{array}{c}\text { Независимая } \\
\text { переменная }\end{array}$} & $\begin{array}{c}\text { Достигаемый уровень } \\
\text { значимости, р-value }\end{array}$ \\
\hline 1 & $\begin{array}{l}\text { Валовая добав- } \\
\text { ленная стоимость } \\
\text { на одного работ- } \\
\text { ника, } \text { млн руб. }\end{array}$ & $\begin{array}{l}\text { Оплата труда } \\
\text { на одного работни- } \\
\text { ка, млн руб. }\left(\mathrm{x}_{6}\right)\end{array}$ & $\mathrm{p}=8,1 \cdot 10^{-6}$ \\
\hline 2 & $\begin{array}{l}\text { Валовая добав- } \\
\text { ленная стоимость } \\
\text { на одного работ- } \\
\text { ника, млн руб. }\end{array}$ & $\begin{array}{l}\text { Расходы на одного } \\
\text { работника, } \text { млн руб. } \\
\left(\mathrm{x}_{7}\right)\end{array}$ & $\mathrm{p}=1,94 \cdot 10^{-16}$ \\
\hline 3 & $\begin{array}{l}\text { Валовая добав- } \\
\text { ленная стоимость } \\
\text { на одного работ- } \\
\text { ника, млн руб. }\end{array}$ & $\begin{array}{l}\text { Условно-перемен- } \\
\text { ные затраты на } \\
\text { одного работника, } \\
\text { млн руб. }\left(\mathrm{x}_{8}\right)\end{array}$ & $\mathrm{p}=8,6 \cdot 10^{-6}$ \\
\hline 4 & $\begin{array}{l}\text { Валовая добав- } \\
\text { ленная стоимость } \\
\text { на одного работ- } \\
\text { ника, млн руб. }\end{array}$ & $\begin{array}{l}\text { Компенсационные } \\
\text { затраты на одного } \\
\text { работника, млн руб. } \\
\left(\mathrm{x}_{9}\right)\end{array}$ & \\
\hline
\end{tabular}

Следует отметить отсутствие связи в исследуемых панельных данных между зависимой переменной у и такими показателями, как условно-постоянные расходы на персонал и инвестиционные расходы на персонал. Это может объясняться тем, что размер данных расходов мал по сравнению с теми, которые оказывают влияние на зависимую переменную, а также тем, что данные расходы финансируются по остаточному принципу, зачастую бессистемно. Данные обстоятельства требуют дополнительного исследования, а также наличия данных, отсутствующих в формах статистической отчетности. Такие данные могут быть получены на предприятиях по распоряжению и с разрешения руководителей.

Далее для параметров, имеющих значимые связи, были выбраны модели, наилучшим образом описывающие имеющиеся зависимости (таблица 2). При выборе моделей были использованы тест Бриша-Пэгана и тест Хаусмана. Сравнительный анализ показал, что перечисленные выше зависимости наилучшим образом описывает модель с фиксированными эффектами (fixed effects regression), позволяющая учитывать неизмеримые индивидуальные различия между предприятиями.

ISSN 2073-6304 • Серия «Экономика. Управление. Право». 2019. № 3 
Параметры моделей, характеризующих

статистически значимые зависимости исследуемых показателей

\begin{tabular}{|c|c|c|l|l|c|}
\hline $\begin{array}{c}\text { № } \\
\text { п/п }\end{array}$ & $\begin{array}{c}\text { Зависимая } \\
\text { переменная }\end{array}$ & Регрессор & \multicolumn{1}{|c|}{ Вид модели } & $\begin{array}{c}\text { Коэффициент } \\
\text { перед } \\
\text { регрессором }\end{array}$ & LSDV R2 \\
\hline 1 & $y$ & $\mathrm{x}_{6}$ & $\begin{array}{l}\text { С фиксированными } \\
\text { эффектами }\end{array}$ & $\begin{array}{l}2,12 \\
\mathrm{p}=3 \cdot 10^{-16}\end{array}$ & 0,88 \\
\hline 2 & $y$ & $\mathrm{x}_{7}$ & $\begin{array}{l}\text { С фиксированными } \\
\text { эффектами }\end{array}$ & $\begin{array}{l}0,85 \\
\mathrm{p}=8,1 \cdot 10^{-6}\end{array}$ & 0,83 \\
\hline 3 & $y$ & $\mathrm{x}_{8}$ & $\begin{array}{l}\text { С фиксированными } \\
\text { эффектами }\end{array}$ & $\begin{array}{l}1,8 \\
\mathrm{p}=1,94 \cdot 10^{-16}\end{array}$ & 0,88 \\
\hline 4 & $y$ & $\mathrm{x}_{9}$ & $\begin{array}{l}\text { С фиксированными } \\
\text { эффектами }\end{array}$ & $\begin{array}{l}0,85 \\
\mathrm{p}=8,6 \cdot 10^{-6}\end{array}$ & 0,83 \\
\hline
\end{tabular}

\section{Интерпретащия результатов}

Результаты анализа панельных данных позволили выявить статистически значимые зависимости и получить модели, пригодные для прогнозирования и принятия управленческих решений в отношении управления затратами на персонал. Полученные коэффициенты могут быть интерпретированы следующим образом:

- при увеличении оплаты труда на одного работника на один рубль валовая добавленная стоимость на одного работника увеличивается в среднем на 2,12 рублей;

- при увеличении расходов на одного работника на один рубль валовая добавленная стоимость на одного работника увеличивается в среднем на 85 копеек;

- при увеличении условно-переменных расходов на одного работника на один рубль валовая добавленная стоимость на одного работника увеличивается в среднем на 1,8 рубля;

- при увеличении компенсационных расходов на одного работника на один рубль валовая добавленная стоимость на одного работника увеличивается в среднем на 85 копеек.

Полученные результаты свидетельствуют о том, что основным фактором формирования добавленной стоимости на исследуемых предприятиях является использование живого труда, в то время как развитие человеческого капитала и инвестиции в него не оказывают существенного влияния на добавленную стоимость. Это 
может означать, что предприятия используют устаревший подход к управлению человеческими ресурсами, характерный для индустриальной экономики, который исчерпал себя в условиях новой экономики и требует пересмотра.

Для более глубокого изучения влияния условно-постоянных и инвестиционных расходов на результат работы организации (добавленную стоимость) в ходе дальнейшего исследования промышленные организации концерна «Беллегпром» были разделены по отраслевому признаку (текстильные предприятия, трикотажные предприятия швейные предприятия, кожевенно-обувные предприятия). Результаты исследования панельных данных, имеющих статистически значимые связи, представлены в таблице 3.

Таблица 3

Параметры моделей, характеризующих статистически значимые зависимости исследуемых показателей по отраслям

\begin{tabular}{|c|c|c|c|c|c|}
\hline $\begin{array}{c}\text { № } \\
\Pi / \Pi\end{array}$ & $\begin{array}{c}\text { Зависимая } \\
\text { переменная }\end{array}$ & Регрессор & Вид модели & $\begin{array}{c}\text { Коэффициент } \\
\text { перед } \\
\text { регрессором } \\
\end{array}$ & Отрасль \\
\hline 1 & $y$ & $\begin{array}{c}\text { Инвестицион- } \\
\text { ные расходы } \\
\text { на одного } \\
\text { работника }\left(\mathrm{x}_{10}\right)\end{array}$ & $\begin{array}{c}\text { Со } \\
\text { случайными } \\
\text { эффектами }\end{array}$ & $\begin{array}{c}59,41 \\
p=0,01\end{array}$ & текстильная \\
\hline 2 & $y$ & $\begin{array}{c}\text { Инвестицион- } \\
\text { ные расходы } \\
\text { на одного } \\
\text { работника }\left(\mathrm{x}_{10}\right)\end{array}$ & $\begin{array}{c}\text { Со } \\
\text { случайными } \\
\text { эффектами }\end{array}$ & $\begin{array}{c}35,74 \\
p=0,0016\end{array}$ & швейная \\
\hline 3 & $y$ & $\begin{array}{c}\text { Условно- } \\
\text { постоянные } \\
\text { расходы } \\
\text { на одного } \\
\text { работника }\left(\mathrm{x}_{11}\right)\end{array}$ & $\begin{array}{c}\text { Со } \\
\text { случайными } \\
\text { эффектами }\end{array}$ & $\begin{array}{c}6,77 \\
\mathrm{p}=0,0019\end{array}$ & текстильная \\
\hline 4 & $y$ & $\begin{array}{c}\text { Условно- } \\
\text { постоянные } \\
\text { расходы } \\
\text { на одного } \\
\text { работника }\left(\mathrm{x}_{11}\right)\end{array}$ & $\begin{array}{c}\text { Со } \\
\text { случайными } \\
\text { эффектами }\end{array}$ & $\begin{array}{c}7,91 \\
\mathrm{p}=9,97 \cdot 10^{-11}\end{array}$ & швейная \\
\hline
\end{tabular}

\section{Интерпретащия результатов}

Полученные результаты свидетельствуют о наличии статистически значимых зависимостей между созданной добавленной стоимостью и инвестициями в персонал, а также между созданной добавленной стоимостью и условно-постоянными расходами на персонал в текстильной и швейной отраслях. Наиболее точно эти связи 
описываются моделью со случайными эффектами. Это означает, что существуют ненаблюдаемые факторы (пропущенные переменные), не коррелирующие с регрессором, влияние которых не выявляется в модели, а отражается в ней через случайные ошибки. Такими факторами могут быть, например, неконтролируемые внешние воздействия (конъюнктуры рынка, колебания спроса и курсов валют, изменения в законодательстве и пр.). Тем не менее полученные в модели коэффициенты могут быть интерпретированы следующим образом:

- при увеличении инвестиционных расходов на одного работника на один рубль в текстильной отрасли валовая добавленная стоимость на одного работника увеличивается в среднем на 59,41 рубля;

- при увеличении инвестиционных расходов на одного работника на один рубль в швейной отрасли валовая добавленная стоимость на одного работника увеличивается в среднем на 35,74 рубля;

- при увеличении условно-постоянных расходов на одного работника на один рубль в текстильной отрасли валовая добавленная стоимость на одного работника увеличивается в среднем на 6,77 рубля;

- при увеличении условно-постоянных расходов на одного работника на один рубль в швейной отрасли валовая добавленная стоимость на одного работника увеличивается в среднем на 7,91 рубля.

Следует отметить, что инвестиционные расходы на персонал, несмотря на наличие ненаблюдаемых факторов, имеют высокую отдачу. Это означает, что персонал действительно является выгодным объектом инвестиций и вложения в персонал обеспечивают более высокую рентабельность, чем прочие объекты инвестирования.

Для более качественной оценки эффективности инвестиций в персонал предлагается использовать динамические модели временных рядов со стационарными переменными (например модель распределенных лагов). При положительных результатах проверки исходных предпосылок о стационарности временного ряда и отсутствии мультиколлинеарности эта модель позволит оценить не только мгновенный, но и накопленный эффект от инвестиций в персонал. При этом потребуется сбор данных об инвестициях в персонал и результатах на регулярной основе за более короткие промежутки времени (например ежеквартально).

Таким образом, проведенное исследование позволило сделать вывод о том, что затраты на персонал и их отдельные элементы оказывают непосредственное влияние на конечные результаты 
деятельности организации. Для повышения эффективности затрат на персонал и качества управления ими необходимо организовать сбор соответствующих эмпирических данных на микроуровне для проведения более глубокого анализа.

\section{Juтература}

1. Армстронг М. Практика управления человеческими ресурсами. 8-е изд. СПб.: Питер, 2007. 832 с.

2. Галешова, E., Ванкевич, E. Кадровая деятельность в организациях Республики Беларусь: Оценка рисков и потенциала // Вестник социальных наук. Даугавпилсский университет. 2015. № 1. С. 23-44.

3. Рыжкова Т.В., Горелова Л.В. Методологические подходы к управлению затратами на персонал организации // Лесной вестник. 2014. № 3. С. 173-182.

4. Aliakseyeva A. Labour cost management as an element of organization's personnel policy // Education and science in the 21st century: Articles of the III International Scientific and Practical Conference. Vitebsk: VSTU, 2018. P. 53-56.

5. Алексеева E.A. Анализ затрат на персонал в легкой и текстильной промышленности Республики Беларусь // Вестник Витебского государственного технологического университета. 2018. № 2 (35). C. 112-122. DOI:10.24411/20797958-2018-13512.

6. Голова А.Г. Макроэкономические факторы, определяющие развитие рынка труда и структуру занятости в России и за рубежом // Вестник РГГУ. Серия «Экономика. Управление. Право». 2018. № 4 (14). С. 52-73. DOI: 10.28995/2073-6304-2018-4-52-73.

7. Зеленова О.И., Просвиркина Е.Ю. Влияние систем управления человеческими ресурсами на финансовые результаты деятельности банков в России // Российский журнал менеджмента. 2017. Т. 15. № 4. С. 463-490.

8. Кащеев П.О., Белгородский В.С., Радъко С.Г. Человеческий капитал как неотъемлемый фактор обеспечения роста производительности труда // Технология текстильной промышленности. 2018. № 3 (375). С. 15-22.

9. Клемина Т.Н. Управление человеческими ресурсами и результаты деятельности организации: теоретические дебаты и эмпирические исследования// Российский журнал менеджмента. 2008. Т. 6. № 3. С. 51-58.

10. Назайкинский С.В. Актуальные проблемы трансформации обучения персонала в организации // Вестник РГГУ. Серия «Экономика. Управление. Право». 2018. № 3 (13). C. 23-34. DOI: 10.28995/2073-6304-2018-3-23-34.

11. Недоспасова О.П. Оценка эффективности корпоративных инвестиций в человеческий капитал в формате сбалансированной системы показателей // Финансовая аналитика: проблемы и решения. 2013. № 14. С. 23-29.

12. Хъюзелид M. Влияние практики управления человеческими ресурсами на текучесть кадров, производительность труда и финансовые результаты компании // Российский журнал менеджмента. 2008. № 6 (3). С. 87-128.

ISSN 2073-6304 • Серия «Экономика. Управление. Право». 2019. № 3 
13. Эфендиев А.Г., Балабанова Е.С., Ребров А.В. Управление человеческими ресурсами и эффективность компаний: есть ли связь? // Российский журнал менеджмента. 2014. Том 12. № 1. С. 39-68.

14. Daniel S. Hamermesh. Do labor costs affect companies' demand for labor? IZA World of Labor. May 2014.

15. Rodrigez J.M., Ventura J. Human resource management systems and organizational performance: An analysis of the Spanish manufacturing industry// International Journal of Human Resource Management. 2003. № 14 (7). P. 1206-1226.

16. Грошева Н.Б., Сафронова С.В., Федорова Е.В. Использование методики ТСО для оценки расходов на персонал // Бизнес-образование в экономике знаний. 2018. № 3 (11). С. 22-28.

17. Назайкинский C.B, Седова O.Л. Роль HR-аналитики в принятии управленческих решений в организациях // Вестник РГГУ. Серия «Экономика. Управление. Право». 2017. № 3 (9). С. 9-19.

18. Назайкинский C.В., Седова О.Л. Совершенствование управления персоналом организации с использованием новых информационных технологий // Вестник РГГУ. Серия «Экономика. Управление. Право». 2016. № 3 (5). С. 76-83.

\section{References}

1. Armstrong M. Human resource management practice. $8^{\text {th }}$ ed. Saint Petersburg: Piter Publ.; 2007. 832 p. (In Russ.)

2. Galeshova E., Vankevich A. Human resources management activities in organizations of the Republic of Belarus: Assessment of the risks and potential. Social Sciences Bulletin. Daugavpils University. 2015;1:23-44. (In Russ.)

3. Ryzhkova TV., Gorelova LV. Methodological approaches to managing the labour costs of an organization. Lesnoy vestnik. 2014;3:173-82. (In Russ.)

4. Aliakseyeva A. Labour cost management as an element of the organization's personnel policy. Education and science in the 21st century. Articles of the III International scientific and sractical conference. Vitebsk: VSTU Publ.; 2018. P. 53-56.

5. Aliakseyeva A. Analysis of labour costs in the cloth, shoe and textile industry of the republic of Belarus. Vestnik of Vitebsk State Technological University. 2018;2(35):112-22. (In Russ.)

6. Golova AG. Macroeconomic factors determining the development of the labor market and the structure of employment in Russia and abroad. RSUH/RGGU Bulletin. “Economics. Management. Law" Series. 2018;4:52-73. DOI:10.28995/20736304-2018-4-52-73. (In Russ.)

7. Zelenova OI., Prosvirkina EYu. The impact of human resources management systems on financial performance of banks in Russia. Russian Management Journal. 2017;15(4):463-90. (In Russ.)

8. Kashcheev PO., Belgorodsky VS., Radko SG. Human capital as an integral factor in ensuring the growth of labor productivity. Technology of the textile industry. 2018;3(375):15-22. (In Russ.) 
9. Klemina TN. Human resource management and the organization performance: Theoretical debate and empirical research. Russian Management Journal. 2008;6(3):51-58.

10. Nazaikinsky SV. Current issues of transformation in personnel training in organizations. RSUH/RGGU Bulletin. "Economics. Management. Law" Series. 2018;3(13):23-34. DOI: 10.28995/2073-6304-2018-3-23-34 (In Russ.)

11. Nedospasova OP. Evaluation of the effectiveness of corporate investment in human capital in the format of a balanced scorecard. Financial analytics: problems and solutions. 2013;14:23-29. (In Russ.)

12. Huselid MA. The impact of human resource management practices on the turnover, labour productivity, and corporate financial performance. Russian Management Journal. 2008;6(3):87-128. (In Russ.)

13. Efendiev AG., Balabanova ES., Rebrov AV. Human resource management and firm performance: Is there any relation? Russian Management Journal. 2014;12(1):39-68. (In Russ.)

14. Daniel S. Hamermesh. Do labor costs affect companies' demand for labor? IZA World of Labor. May 2014. (In Russ.)

15. Rodrigez JM., Ventura J. Human resource management systems and organizational performance: An analysis of the Spanish manufacturing industry. International journal of human resource management. 2003;14 (7):1206-26.

16. Grosheva NB., Safronova SV., Fedorova EV. Using the TCO methodology to estimate staff costs. Business education in the knowledge economy. 2018;3(11):2228. (In Russ.)

17. Nazaykinsky S., Sedova O. The role of HR-analytics in making the administrative decisions in organizations. RSUH/RGGU Bulletin. "Economics. Management. Law" Series. 2017;3(9):9-19. (In Russ.)

18. Nazaykinsky S., Sedova O. Development of human recourse management through the use of new information technologies. RSUH/RGGU Bulletin. "Economics. Management. Law” Series. 2016;3(5):76-83. (In Russ.)

\section{Информащия об авторе}

Елена А. Алексеева, магистр экономических наук, Витебский государственный технологический университет, Витебск, Беларусь; 210038, Беларусь, Витебск, Московкий пр-т, д. 72; elena_d@tut.by

\section{Information about the author}

Alena A. Alekseeva, master of Economics, Vitebsk State Technological University, Vitebsk, Belarus; bld. 72, Moskowskii Avenue, Vitebsk, Belarus, 210038; elena_d@tut.by 